\title{
Infantile glycine encephalopathy
}

INSERM

\section{Source}

INSERM. (1999). Orphanet: an online rare disease and orphan drug data base. Infantile glycine encephalopathy. ORPHA:289860

Infantile glycine encephalopathy is a mild to severe form of glycine encephalopathy (GE; see this term), characterized by early hypotonia, developmental delay and seizures. 